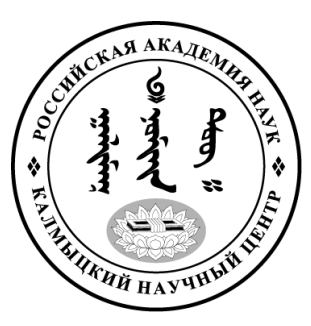

Published in the Russian Federation

Oriental Studies (Previous Name: Bulletin of the Kalmyk Institute for

Humanities of the Russian Academy of Sciences)

Has been issued as a journal since 2008

ISSN: 2619-0990; E-ISSN: 2619-1008

Is. 3, pp. 441-449, 2019

DOI: $10.22162 / 2619-0990-2019-43-3-441-449$

Journal homepage: https://kigiran.elpub.ru

УДК 821.512 .37

\title{
Списки рукописей и история публикации «Истории Усун Дебискерту-хана»
}

\author{
Баазр Александрович Бичеев \\ ${ }^{1}$ Калмыцкий научный центр РАН (д. 8, ул. И. К. Илишкина, 358000 Элиста, Российская Федера- \\ ция) \\ доктор философских наук, ведущий научный сотрудник \\ ORCID: 0000-0002-9352-7367. E-mail: bazar@mail.ru
}

\begin{abstract}
Аннотация. Введение. В старописьменной монгольской литературе особой популярностью пользовались тексты дидактического содержания. Они создавались монгольскими авторами на основе образцов древнеиндийской дидактической литературы. В таких наставлениях три основные ценности - дхарма, артха и кама - должны находиться в постоянном равновесии. Однако один из этих факторов всегда должен быть ведущим. Составной частью apmxamacmpbl была нитишастра как самостоятельная наука о политике и управлении страной. Однако в монгольской литературе соединение двух правил - светского и религиозного стало характерным признаком дидактического жанра. Богатое и разнообразное наследие монгольской дидактической литературы, согласно утвердившейся традиции, стало называться «поучениями двух правил». Даже если в таких произведениях религиозные наставления не занимали заметного места, конечная цель авторами этих текстов объяснялась вполне в духе буддийской дхармы. Одним из известных произведений дидактической литературы можно назвать «Историю Усун Дебискерту-хана». Цель статьи - введение в научный оборот данных о списках рукописей ойратской версии «Истории Усун Дебискерту-хана», истории публикации текста произведения и его устных вариантах. Решаемые задачи: поиск и выявление списков рукописей «Истории Усун Дебискерту-хана» на «ясном письме», данных о публикации текста и фиксации устных вариантов произведения. Основной метод исследования - поисковый подход и метод сравнительно-сопоставительного анализа. Результаты поискового этапа: 1) о широкой распространенности произведения свидетельствуют тринадцать списков этого текста, выявленных в коллекциях ойратских рукописей Монголии, России и Китая; 2) публикация текста памятника была осуществлена представителями калмыцкого зарубежья в 1926 г; 3) устный вариант предания о легендарном тибетском царе Усун Дебискерту-хане был опубликован в русском переводе в 1810 г. Bblводыl. На основе списков тринадцати рукописей, обнаруженных в ходе поисковой работы, выявлено, что произведение пользовалось широкой популярностью во всех трех ареалах бытования ойратов (Монголия, Россия и Китай). Также о популярности произведения свидетельствует зафиксированное у волжских калмыков в начале XX в. устное предание о легендарном тибетском царе Усун Дебискерту-хане.

Ключевые слова: буддизм, дидактическая литература, перевод, рукопись, списки рукописей Благодарности. Исследование проведено в рамках государственной субсидии - проект «Устное и письменное наследие монгольских народов России, Монголии и Китая: трансграничные традиции и взаимодействия» (номер госрегистрации: АААА-А19-119011490036-1)/
\end{abstract}


Для цитирования: Бичеев Б. А. Списки рукописей и история публикации «Истории Усун Дебискерту-хана». Oriental Studies. 2019;(3): 441-449. DOI: 10.22162/2619-0990-2019-43-3-441449.

UDC 821.512.37

\title{
'The Story of Usun Debiskertu Khan': Manuscript Copies and History of Publication
}

\author{
Baazr A. Bicheev ${ }^{1}$ \\ ${ }^{1}$ Kalmyk Scientific Center of the RAS (8, Ilishkin Str., Elista 358000, Russian Federation) \\ Dr. Sc. (Philosophy), Leading Research Associate \\ ORCID: 0000-0002-9352-7367. E-mail: bazar@mail.ru
}

\begin{abstract}
Introduction. In old Mongolian literature, texts of didactic texts enjoyed special popularity. Those were created by Mongolian authors following the examples borrowed from ancient Indian didactic literature. In such tutorials the three basic values - Dharma, artha and kama - are to be in constant balance. However, one of these factors should always be leading. The nitisastra was an integral part of the arthasastra as an independent science about politics and governance. Still, in Mongolian literature, it is the combination of two instructions - secular and religious ones - that became characteristic to the didactic genre. The rich and diverse heritage of Mongolian didactic literature, according to the established tradition, became known as 'teachings of the two rules'. Even if in such works religious instructions did not occupy any prominent place, the ultimate goals of such texts could well be interpreted in the spirit of the Buddhist Dharma. So, 'The Story of Usun Debiskertu Khan' is a most famous work of didactic literature. According to the contents of the monument, the legendary Khan of Tibet had delivered the teachings during a conversation with sixteen dignitaries of his. The text of the monument was translated into Oirat after the creation of the Clear Script (1648) but it could have also been translated into Classical Mongolian in the early-to-mid $17^{\text {th }}$ century. The thirteen manuscript copies of the text discovered in collections of Oirat manuscripts throughout Russia, Mongolia and China attest to the popularity and wide distribution of this work. At the same time, the work can be found both in the form of separate manuscripts and within literary collections which, as a rule, had comprised most famous and beloved texts. The Story was first published by representatives of the Kalmyk expatriate community in the early $20^{\text {th }}$ century.

Keywords: Buddhism, didactic literature, translation, manuscript, manuscript copies

Acknowledgements: Research was performed within a government subsidy — project name 'Oral and Written Heritage of Mongolic Peoples of Russia, Mongolia and China: Cross-Border Traditions and Interactions' (State Reg. No. AAAA-A19-119011490036-1).

For citation: Bicheev B. 'The Story of Usun Debiskertu Khan': Manuscript Copies and History of Publication. Oriental Studies. 2019;(3): 441-449. DOI: 10.22162/2619-0990-2019-43-3-441-449.
\end{abstract}

\section{子}

\section{Введение}

Произведения дидактического содержания составляют своеобразный пласт старописьменной монгольской и ойратской литератур. Тексты подобного вида пользовались особой популярностью и широкой распространенностью среди любителей книжной старины. Вполне естественно, что они оказались в поле исследования современно- го монголоведения [Бадмаев 1984; Ёндон 2013; Цэрэнсодном 1976].

Известный монгольский ученый Д. Ёндон в своей работе, посвященной комментариям к двум дидактическим трактатам «Капле, питающей людей» и «Субхашите», пишет, что образцы древнеиндийской дидактической литературы, послужили источником творческого вдохновения для 
средневековых тибетских и монгольских авторов, оставивших после себя богатое и разнообразное наследие [Ёндон 2013: 5].

Дидактическая литература была тесно связана с индийской философией, которая признавала три основные ценности в жизни человека: дхарма (санск. dharma) - духовное служение на благо общества и наука; польза (санск. artha) — накопление материальных благ; любовь (санск. kama) - учение о чувственных наслаждениях. Позднее к ним добавилась четвертая ценность спасение (санск. moksa).

В таких наставлениях три основные ценности - дхарма, польза и любовь должны находиться в постоянном равновесии. Однако один из этих факторов всегда должен был быть ведущим [Кальянов 1959: 569].

Этим трем ценностям соответствовали три системы знаний: дхармашастра, артхашастра и камашастра. Составной частью артхашастры была нитишастра как самостоятельная наука о политике и управлении страной. Д. Ёндон отмечает, что слияние местной и индийской традиции послужило возникновению несколько иного жанра дидактической литературы. Соединение двух правил - светского и религиозного, стала характерным признаком этого жанра. Поэтому нитишастры в Тибете и Монголии стали называться «поучениями двух правил». «Любые сочинения, созданные по типу индийских нитишастр и призванные учить житейской мудрости, здесь сочетаются „поучениями двух правил“, даже если в них дхарме отводится незначительное место или она вовсе отсутствует, поскольку поэты объясняли конечную цель таких поучений вполне в духе дхармы» [Ёндон 2013: 5].

В узком утилитарном смысле такие произведения представляют собой сборник стихотворных наставлений о добродетельной жизни и мудрости. Образцы этого жанра не только включались тибетцами и монголами в буддийские каноны, но и издавались отдельно, переписывались и имели широкое хождение в рукописном виде.

Публикация текстов наставлений на «ясном письме»

О популярности произведений дидактического содержания свидетельствует содержание «Калмыцкой хрестоматии для чтения в аймачных и в младших отделениях улусных школ». Она была составлена учителем калмыцкой школы Ш. Болдыревым в 1906 г., но в силу обстоятельств была опубликована спустя два десятка лет. Единственный рукописный экземпляр хрестоматии Ш. Болдырева сохранился в архиве известного монголиста В. Л. Котвича. После октябрьских событий 1917 г. он переехал в Польшу и поддерживал активную связь с представителями калмыцкой эмиграции. Летом 1927 г. Калмыцкая комиссия культурных работников в эмиграции получила от профессора В. Л. Котвича рукопись хрестоматии. Признавая большую ценность учебника, комиссия издала ее в 1927 г. в третьем выпуске «Хонхо» [Калмыцкая хрестоматия 1927].

Ш. Болдырев включил в содержание своего учебника образцы наиболее известных произведений старописьменной калмыцкой литературы: наставления, буддийские притчи, биографии учителей буддизма, историческое сочинение «История Убаши-хунтайджия и его войны с ойратами», сборник обрамленных рассказов «Волшебный мертвец» из двенадцати сюжетов. Все приведенные им в хрестоматии образцы текстов заимствованы им из калмыцких рукописей. По всей вероятности, Ш. Болдырев имел доступ к личным библиотекам калмыцких князей Ц.-Д. Тундутова и С.-Д. Тюменя, к хранилищам рукописей буддийских монастырей Малодербетовского и Хошеутовского улусов и к личным коллекциям любителей книжной старины, о которых сообщает в своих отчетах Н. Очиров [Очиров 1910; Очиров 1913].

Хрестоматия Ш. Болдырева состоит из двух частей. Для удобства чтения материалы разделены на отдельные параграфы. В первой части (§§ 1-58) даны слоги, односложные слова, краткие предложения. Затем следуют переводные материалы (§§ 59-107) из «Русской речи» М. Вольпера, «Книги для чтения» Л. Н. Толстого и басен И. А. Крылова ${ }^{1}$. В эту первую часть вкраплены четыре калмыцких материала: исторические предания о Мазан-баторе (§ 94) и хошеутовском Гуши-хане (§ 96), сказочный сюжет о ведь-

${ }^{1}$ Интересно, что переводы басен И. А. Крылова присутствуют во многих учебниках для национальных школ того времени [Авидзба 2016: 96-97]. 
ме (§ 95), легенда о происхождении ойратов $(\S 100)$.

Литературные произведения, вошедшие во вторую часть хрестоматии, как отмечено самим составителем «заимствованы из старинных калмыцких писаний» [Калмыцкая хрестоматия 1927: 66]. Большинство текстов представляют собой образцы дидактической литературы:

- «Ключ разума» («Oyuni tulkür kemekü orošiboi»). В Хрестоматии текст этого сборника наставлений наставления разбит на два параграфа (§ 108, § 113), которые помещены под одним названием «Пословицы» $(« \ddot{U l} l g \ddot{u} r m \ddot{u ̈} d »)^{2}$;

- «Наставления учителя-наставника $^{3}$ Седкелин-хану» (§ 110 «Buyani sadun Sedkeliyin xāndu eyin kemēn zarliq bolbo»);

- «Усень Дебискерту хана» $»^{4} \S 111$ 112 «Üsün Debeskertü xān»);

- «Субхашита» (\$ 114 «Sayitur nomloxo erdemiyin sang»);

- «Поучения Чингис-хана братьям и сыновьям» (§ 115 «Boqdo Činggis $x \bar{a} n$ dü̈̈ner bolon köbüüd-yēn suryān zarliq boloqson inu»).

${ }^{2}$ В предисловии к хрестоматии Ш. Болдырев пишет: «Нравоучительные пословицы, сказания и сказки заимствованы из древних калмыцких рукописей, а потому орфография сохранена в целости» [Калмыцкая хрестоматия 1927: XVII]. При подготовке хрестоматии к изданию были внесены некоторые изменения. «Сохраняя полностью содержание (за исключением калмыцко-русского словаря) хрестоматии Ш. Болдырева, Комиссия лишь считает нужным соблюсти принятую в предыдущих своих изданиях орфографию калмыцкого письма» [Калмыцкая хрестоматия 1927: IV]. При этом были допущены пропуски слов, иногда строк в текстах некоторых произведений. К сожалению, поиски оригинала рукописи «Калмыцкой хрестоматии» Ш. Болдырева пока не принесли успеха.

3 Учитель-наставник (санскр. kalyāṇa-mitra; тиб. dge ba'i bshes gnyen; ойр. buyani sadun; букв. Сын добродетели) - Духовный наставник, Учитель.

${ }^{4}$ При переложении этого текста на современный калмыцкий язык выяснилось, что при публикации хрестоматии Ш. Болдырева были допущены пропуски слов и строк в тексте произведения [Бичеев 2003: 117].
- «История Огелегу Бедерегчи хана» (§ 116 «Öqligö Bedereqči sayin xāni tuuji»).

- «Будда и брахман» (§117 «Burxan birman xoyor»).

- «Правитель благословенной страны Хашанг-хан» (§ 118 «Bayasxalangtu oroni Xašing neretei xān»)).

- «Восхваление Чингис-ханом своих сподвижников» (§ 119 «Činggis Boqdo xān yaraǰi tüšimelmüü-dēn maqtadaq bölögei»)

- «Законы существования материального и органического миров» (§ 122 «Orčilonggin saba šimiyin axa yoson»).

Таким образом, хрестоматию Ш. Болдырева можно назвать первым печатным сборником произведений старописьменной калмыцкой литературы. Автор, тщательно продумав содержание хрестоматии, включил в нее образцы разных жанров национальной словесности. Неслучайно, один из лидеров калмыцкой эмиграции С. Б. Баянов отмечал, что «история политическая и история культурная, образцы практической мудрости народа - все это нашло свое место в кропотливом, вдумчиво составленном труде Шургучи Болдырева» [Калмыцкая хрестоматия 1927: XII].

В 2005 г. Д. Ганболд издал сборник произведений «,История принца Оюн Чикиту“и другие избранные произведения монгольской литературы» («,Оюу Чихт хан хөвүYний туужс " тергуүтэн монголын сонгодог уран зохиольин хэдэн дурсхал»). В книге опубликованы тексты рукописей из ойратской коллекции кафедры монгольской литературы Ховдского государственного университета. Кроме «Истории принца Оюн Чикиту» (также известного как «История Унэкер Торликту-хана») в сборник вошли еще десять произведений, среди которых три текста наставлений - «Повесть о трехлетнем мальчике» («Гurban nastu kü̈̈keni touji orošiboi»), «Притча о гневном брахмане» («Doqšin birman-ni tuuji») и «История Усун Дебискерту-хана» («Üsün debiskirtü-yin tuијi оrošibo») [Ганболд 2005].

Еще одним сборником, в котором опубликовано одиннадцать известных произведений жанра наставлений и двадцать пять текстов воскурений на «ясном письме», следует назвать сборник «Поэтические тексты наставлений и воскурений» («Surjal silüg 
kiged sang takil»), изданный синьцзянским исследователем До. Галданом. В эту книгу вошли тексты, которые хранятся в коллекции ойратских рукописей г. Урумчи (СУАР KHP).

Назовем лишь некоторые из этих произведений: «История Усун Дебискерту-хана» («Üsün debiskirtü-yin tuuji orošibo»); «Законы существования материального и органического мира» («Saba šimiyin axu yosoni tuuј̌ orošiboi»); «Хрустальное зерцало, наставляющее обретение и утрату [при соблюдении] двух правил» («Хог̆ yosuni abxu gēküyigi nomloqson cayān šel toli orošibo»); «Наставления Нагарджуны» («Nayazunayin zarliq orošibo»); «Наставления (лунгдун) богдо Джибзун Дамбы» («Boqdo Jibzun damba-yin lungdun orošiboi»); «Ключ к шастре наставлений тринадцати великих сановников» («Arban yurban yeke tüšimeliyin šaštir önisüni tülkür») и др. [Galdan 2013].

Опубликованные в двух вышеуказанных изданиях произведения - лишь небольшая часть известных в ойратской литературе сочинений жанра наставлений или «поучений двух правил».

\section{Публикация текста «Истории Усун Дебискерту-хана»}

Среди опубликованных в «Калмыцкой хрестоматии» Ш. Болдырева и книге До. Галдана наставлений, мы видим одно из наиболее известных и распространенных произведений дидактической литературы - «Историю Усун Дебискерту-хана». О популярности этого произведения среди волжских калмыков свидетельствуют отчеты известного калмыцкого ученого Н. Очирова о его поездках летом 1909 г. и 1911 г. в Малодербетовский и Александровский улусы астраханских калмыков. В числе рукописей, приобретенных им для библиотеки Санкт-Петербургского университета в Малодербетовском улусе, под № 15 значится «История Усун Дебискерту-хана» («Yсн Девскрт хаана туужсџ) [Очиров 1910: 77]. В числе рукописей, купленных в Александровском улусе, под № 25а также значится «История Усун Дебискерту-хана» («Yсн Девскрт хаана туужс») [Очиров 1913: 90].

Еще одним свидетельством широкого хождения этого произведения является русский перевод притчи о легендарном Усун Дебискерту-хане. Она была опубликована под названием «Водопад и дикий камень» в приложении к книге главного пристава калмыцкого народа Н. И. Страхова [Страхов 1810: 69-73]. Этот же русский перевод с исправлениями и под названием «Водопад и камень» опубликовал Н. Бадмаев (ум. в 1912 г.) в сборнике «Калмыцкие сказки», подготовленном им по случаю 50-летия Астраханского калмыцкого училища [Бадмаев 1899: 5-6]. Как в первой, так и во второй публикации нет указаний на источник, с которого был сделан перевод притчи.

В 1984 г. во втором номере журнала «Хан Тенгер», который издавался в Синьцзян-Уйгурском автономном районе Китая на «ясном письме», был опубликован текст «Истории Усун Дебискерту-хана» [Üsün debiskertü 1984: 4-21].

Рукопись, с которого делалось переложение, хранилась в личной коллекции учителя Ни. Басана. Впоследствии он передал одиннадцать рукописей из своей коллекции в дар Кабинету по сбору, каталогизации и изданию письменных памятников национальных меньшинств СУАР КНР [Бичеев $2011]$.

Текст «Истории Усун Дебискерту-хана» хранится под шифром XGMO: 0220. Факсимиле этой рукописи опубликовано в вышеупомянутой книге До. Галдана [Galdan 2013: 187-210].

Списки рукописей «Истории Усун Дебискерту-хана»

В центрах хранения монгольских рукописей России, Монголии и Китая на сегодня выявлено тринадцать списков «Истории Усун Дебискерту-хана» на «ясном письме». Интересно, что произведение встречается как в виде отдельных рукописей, так и в составе литературных сборников, что служит еще одним указанием на популярность этого произведения и его широкую распространенность в прошлом.

Пять списков этого текста находятся в Монголии. В коллекции ойратских рукописей Института языка и литературы АН Монголии три текста:

№ 84. Üsün debiskertü xāni tuuji orošiboi:

«История Усун Дебескирту-хана»

Ойр. рук., 12 л., 34 х 11 (27.5 x 7.5), 32 стк., рус. бумага, черная тушь.

[Gerelmaa 2005: № 1016]. 
№ 445a. Üsün debiskertü xāni tuuji orošiboi: «История Усун Дебискерту-хана»

Ойр. рук., 11 л., 34 х 10.5 (29 х 8), 31 стк., рус. бумага, черная тушь.

[Gerelmaa 2005: № 1017].

№ 827 [99]. Üsün debiskertü xāni tuuǰ orošiboi:

«История Усун Дебискерту-хана»

Ойр. рук., 6 л., 22.5 x 8 (20.5 x 5), 20 стк., рус. бумага, черная тушь.

[Gerelmaa 2005: № 1018].

В коллекции ойратских рукописей кафедры монгольской литературы Ховдского государственного университета (Монголия) сохранился лишь один список.

4. ТоБ № 88. Üsün debiskertü xāni tuuji orošiboi:

История Усун Дебискерту-хана»

Ойр. рук., 13 л., 29.7 х 8.6 (26 x 6.6), 24-25 стк., кит. бумага, черная тушь.

[Ганболд 2005: 92].

Текст этой рукописи на современной монгольской графике был опубликован исследователем Д. Ганболдом в вышеупомянутом сборнике [Ганболд 2005: 92-100].

В личной коллекции школьного учителя из сомона Жаргалант Ховдского аймака Н. Цэвгэ хранится еще одна рукопись «Истории Усун Дебискерту-хана».

Личная коллекция Н. Цэвгээ (Ховд аймак, сомон Жаргалант):

Üsün debeskertü xān arban xoyor tüšimed-lügē ögüüleqsen yoson orošibai:

«История Усун Дебискерту-хана»

Ойр. рук., 13 л., 22 х 7.7, 27 стк., потемневшие листы, черная тушь.

[Цэвгээ 2003: 95-107].

В 2003 г. Н. Цэвгээ на свои средства небольшим тиражом издал книгу «Принятие буддизма и эволюция ойратской культуры и общества» («Ойрадад анх шарын шашин ҮҮссэн, соёл, нийгэм төрийн хувьсал〉), в которой опубликовал факсимиле нескольких текстов на «ясном письме», в том числе и «Историю Усун Дебискерту-хана». По всей видимости, рукопись из коллекции Н. Цэвгээ - это наиболее ранний из известных на сегодня списков этого текста. Бумага настолько потемнела, что местами текст читается с трудом [Цэвгээ 2003: 95-107].

В фонде ойратских рукописей Кабинета по сбору, каталогизации и изданию пись- менных памятников национальных меньшинств СУАР КНР находятся два списка «Истории Усун Дебискерту-хана».

XGMO: 0219 Üsün debiskirtü-yin tuuji:

Переводчик: Ariya diva güüši

Ойр. рук., 17 л., 27 х 11.5 (22 х 8.5), 17 стк., кит. бумага, черная тушь, калам.

[Galdan 2013: 187]

XGMO: 0220 Üsün debiskirtü-yin tuuji orošibo:

Переводчик: Ariya diva güüši .

Ойр. рук., 23 л., 25 х 10.5, 16 стк., кит. бумага, черная тушь, калам.

[Galdan 2013: 187]

Факсимиле рукописи XGMO: 0220 и переложение текста на монгольскую графику опубликовано в книге До. Галдана [Galdan 2013: 187-210]. Эта та самая рукопись, которая была подарена учителем Ни. Басаном.

В отечественных коллекциях рукописей на «ясном письме» сохранилось шесть списков этого памятника. При этом только два текста представляют собой отдельные рукописи. Остальные четыре входят в состав разных литературных сборников.

В Институте восточных рукописей РАН «История Усун Дебискерту-хана» находится в составе трех ойратских литературных сборников. Рукопись небольшого по объему сборника E 6 из коллекции Н. Очирова состоит из двух наиболее популярных произведений - «Истории Усун Дебискерту-хана» и «Притчи о Будде и брахмане» («Burxan baqši birman xoyorin tuuji»).

Е 6 (Очиров, 25), инв. № 1261

1. Начало (Л. 2а):... tö̈̈ni gekü: züq kümün yambar bolxu bui kemebēsü...

Переводчик: Ariya diva güüsi $i$.

Перевод: потс̌i kündülen Xurmustun xān.

2. Начало (л. 8а): Urida nigen caqtu burxan badir bariǰi nigen geriyin ö̈̈den-dü kürün...

Джатака о Будде и брамине.

Ойр. рук., тетрадь, л. 2-11 (нет конца), 35.5 х 22 (33 x 18), 23-26 стк., рус. бумага,

Коричневые чернила, перо.

[Сазыкин 1988: № 302 (1)].

Второй литературный сборник $\mathbf{E} 90$ также из коллекции Н. Очирова состоит из шести текстов - «История субургана Джарон-кашур» («Yeke suburyan ByarongKašoriyin eši sonoson getülkü kemēkü»)); «Из- 
влечения из [сочинения] о Чистой земле (Сукавади)» («Ariun tarālanggiyin nomiyin züyil»); «Истории Унэкер Торликту-хана» («Ünekēr törölkitü sayin xāni tuuji orošiboi»); «Субхашита» («Sayitur nomloxoi erdeni-yin sang kemekü šastar»); «История Усун Дебискерту-хана» («Usun Debeskertü xāna tuијі») и «Поучения Чингис-хана» («Yeren yesün tenggeriyin oron-ēce...»).

E 90 (Коллекция Очирова, 31).

5. Usun debiskertü xān (л. 124б).

«Повесть об Усун-дэбискерту-хане» (л. 115б-124б).

Ойр. рук., 130 л., 32,5 х 20, 25 стк., рус. бумага, чернила, перо.

[Сазыкин 1988: № 425(5)]

Третий литературный сборник D 22 включает в себя восемь произведений дидактического содержания. Седьмым в этом сборнике значится «История Усун Дебискерту-хана».

D 22 (Коллекция Позднеева, 263).

7. Usun debiskertü xāni nomloqsan šaštar orošiboi» (л. 50a).

«Повесть об Усун-дэбискерту-хане» (лл. $50 \mathrm{a}-57 \mathrm{a})$.

Переводчик: Arya-diva.

Ойр. рук. в европ. переплете, 62 л. + обложка, 19.8 х 16 (18 x 12.8), 18-26 стк., европ. Бумага с филигранью «1843», «Baih Fine», чернила, перо.

[Сазыкин1988: № 427 (7)].

Два списка «Истории Усун Дебискерту-хана» хранятся в отделе по направлению «Востоковедение» Научной библиотеки им. М. Горького СПбГУ. Один текст входит в состав литературного сборника на «ясном письме», состоящего из шести произведений различного содержания. «История Усун Дебискерту-хана» расположена второй по счету.

Calm. В 10. Сборник различных историй и нравственных заповедей.

Коллекция Голстунского (1856), №. 30.

Ойр. рук.; книга; пагинации нет; 17.5 х 21.2; 18-21 стк.

(2) Üsün debesekertü xāni nomloqsan šaštir orosibo.

Ff. 9a-19a.

Переводчик: Ārya Diva güüsi.

[Uspensky 1999: N 948(2)]
Второй текст представляет собой ойратскую рукопись в европейском переплете.

Calm. C 16. (f. 13a) < Üsün debeskirtü xān: ulus irgen-dü nom yertüncüyin yoso üzüülkü caqta: arban xoyor tīšimed-lügē ügüüleldüqsen yosoni $[\ldots]>$.

Повесть об Усун Дебискерту-хане.

Ойр. рук. в европейском переплете; лл. 1-13b; 35 х 21.7; 29-31 стк.

Переводчик: Ārya Diva güüsi.

[Uspensky 1999: N 423].

Одна рукопись хранится в Научном архиве Калмыцкого научного центра РАН [НА КалмНЦ РАН. Ф. 15. Оп. 3. Ед. хр. 148].

Üsün debiskertü xāni nomloqson šaštir kemekü orošiba

Шастра об Усун дэбискерту-хане.

Ойр. рук., 17 л., 21,5х8, 20-21 стк., бумага серая, тушь черная, перо.

[Орлова 2002: N 25]

\section{Заключение}

Тексты дидактического содержания составляют большой пласт старописьменной калмыцкой литературы. Одним из известных произведений этого вида литературы является «История Усун Дебискерту-хана». Ойратский перевод наставления, несмотря на его широкое хождение в рукописном виде, остался вне поля зрения исследователей. До. Галдан и Д. Ганболд, опубликовавшие два списка этого текста, сообщают лишь общие сведения о содержании памятника. Между тем необходимо решить вопрос авторства ойратского перевода, исторического содержания текста и провести сопоставительный анализ всех известных монгольских и ойратских рукописей «Истории Усун Дебискерту-хана».

Авидзба 2016 - Авидзба В. Ш. Литературные горизонты: статьи, интервью, выступления. Сухум: Абгосиздат, 2016. 224 с.

Бадмаев 1899 - Сборник калмыцких сказок (На русском языке). Составил Найман Бадмаев. Астрахань: Губернская типография, 1899. $110 \mathrm{c}$.

Бадмаев 1984 - Бадмаев А. В. Калмыцкая дореволюционная литература. Изд. 2-е, исп., доп. Элиста: Калм. кн. изд., 1984. 168 с.

Бичеев 2003 - Бичеев Б. А. Этнообразующие доминанты духовной культуры западных 
монголов (ойратов). Элиста: КалмГУ, 2003 $204 \mathrm{c}$.

Бичеев 2011 - Бичеев Б. А. Фонд ойратских рукописей Комитета по делам национальностей СУАР КНР // Память мира: историко-документальное наследие буддизма. Сборник трудов конференции. М.: ООО «Изд. Ипполитова», 2011. С. 240-244.

Ганболд 2005 - «Оюу Чихт хан хөвүүний тууж» тергүүтэн монголын сонгодог уран зохиолын хэдэн дурсхал (= «История принца Оюн Чикиту» и другие избранные произведения монгольской литературы). Эмхэтгэж, хэвлэлд бэлтгэн, тайлбар сэлт үйлдсэн Д. Ганболд. Улаанбаатар: ХИС, 2005. 113 с.

Ёндон 2013 - Ёнон Д. Сказочные сюжеты в памятниках тибетской и монгольской литератур. 2-е изд. Улаанбаатар: ИЯЛ АНМ, 2013. $201 \mathrm{c}$.

Кальянов 1959 - Артхашастра, или наука политики. Пер. с санскрита. Изд. подготовил В. И. Кальянов. М.; Л.: Изд-во АН СССР, 1959. 793 c.

Орлова 2002 - Орлова К. В. Описание монгольских рукописей и ксилографов, хранящихся в фондах Калмыкии // Бюллетень Общества востоковедов. Вып. 5. М.: Институт востоковедения РАН, Калмыцкий институт гуманитарных исследований РАН, 2002. 85 с.

Очиров 1910 - Отчет о поездке Н. Очирова к Астраханским калмыкам летом 1909 года // Известия Русского комитета для изучения Средней и Восточной Азии. СПб., 1910. Март. С. 61-75.

Очиров 1913 - Поездка в Александровский и Багацохуровский улусы Астраханских калмыков. Отчет Н. Очирова // Известия Русского комитета для изучения Средней и Восточной Азии. СПб., 1913. Сер. II, № 2. C. $78-91$.

Сазыкин 1988 - Сазыкин А. Г. Каталог монгольских рукописей и ксилографов Института востоковедения АН СССР. Т. І. М.: Наука, ГРВЛ, 1988. 507 с.

Страхов 1810 - Нынешнее состояние калмыцкого народа, с присовокуплением калмыцких законов и судопроизводства, десяти правил их веры, молитвы, нравоучительной повести, сказки, пословиц и песни Савардин. Сочинил и издал Николай Страхов. СПБ.: Типография Шнора, 1810. 95 с.

Калмыцкая хрестоматия 1927 - Калмыцкая хрестоматия для чтения в аймачных и в младших отделениях улусных школ. Сост. Ш. Болдырев // Хонхо. Вып. III. Прага: Изд. КККР в ЧСР, 1927. 255 с.
Цэвгээ 2003 - Цэвгээ H. Ойрадад анх шарын шашин үүссэн, соёл, нийгэм төрийн хувьсал (= Принятие буддизма ойратами и эволюция культуры и общества). Улаанбаатар, 2003. $220 \mathrm{c}$.

Цэрэнсодном 1976 - Цэрэнсодном Д. Сургаалын шүлэг (= Поэтические наставления) // Монголын уран зохиолын тойм. Хоёрдугаap дэвтэр (XVII-XVIII з. ү.). Улаанбаатар: ШУАХ, 1976. C. 70-92.

Galdan 2013 — Galdan Do. Üsün debiskertü qayan-u tuүuǰi orosiba (= История Усун Дебискерту-хана) // Suryal silüg kiged sang takil. Todu üsüg-ün erten-u dursxal bičig-ün

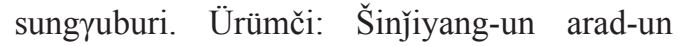
keblel-ün xoryi-a, 2013. C. 3-19.

Gerelmaa 2005 - Gerelmaa G. Brief Catalogy of Oirat Manuscripts Kept by Institute of Language and Literature bu Gerelmaa Guruuchin. Ulaanbaatar: Institute of language and literature, Academy of Sciences of Mongolia, 2005. 270 p.

Uspensky 1999 - Uspensky $V$. Catalogue of the Mongolian Manuscripts and Xylographs in the St. Petersburg State University Library. Tokyo: Institute for the Study of Languages and Cultures of Asia and Africa, 1999. 530 p.

Üsün debiskertü 1984 - Üsün debiskertü xāni tuuj̆i orošibai (= История Усун Дебискерту-хана) // Xan Tenggeri. № 2. Urumči: Ardiyin kebleleiyin xoro, 1984. C. 4-21.

\section{References}

['The Story of Oyu Chikt Khan' and Other Selected Works of Mongolian Literature]. D. Ganbold (prep., comment.). Ulaanbaatar: Khovd State Univ., 2005. 113 p. (In Mong.)

[A Description of the Current State of the Kalmyk People, Supplemented with Texts of Kalmyk Laws and Legal Procedures, the Ten Precepts of Their Faith, a Prayer, a Didactic Novel, a Fairy Tale, Proverbs and the Song 'Savardin'. Comp. and publ. by Nikolai Strakhov]. St. Petersburg: I. Schnor, 1810. 95 p. (In Russ.)

[A Kalmyk-Language Reader for Students of Aimag and Junior Ulus Schools. Comp. by Sh. Boldyrev]. In: Khonkho. Is. III. Prague: Commission of Kalmyk Cultural Workers in Czechoslovak Rep., 1927. 255 p. (In Kalm.)

[Arthashastra, or Science of Politics]. Transl. from Sanskrit. Prep. by V. I. Kalyanov. Moscow, Leningrad: USSR Acad. of Sc., 1959. 793 p. (In Russ.)

[Kalmyk Fairy Tales Collected by Naiman Badmaev]. Astrakhan: Governorate Print. House, 1899. 110 p. (In Russ.) 
'The Story of Usun Debiskertu Khan'. Xan Tenggeri. No. 2. Urumqi: Xinjiang People's Publ. House, 1984. 203 p. (In Mong.)

Avidzba V. Sh. [The Literary Horizons: Articles, Interviews, Speeches]. Sukhumi: Abkhaz State Publ. House, 2016. 224 p. (In Russ.)

Badmaev A. V. [Kalmyk Pre-Revolutionary Literature]. $2^{\text {nd }}$ ed., rev. and suppl. Elista: Kalm. Book Publ., 1984. 168 p. (In Russ.)

Bicheev B. A. [Spiritual Culture of the Western Mongols (Oirats): Ethnos Formation Dominants]. Elista: Kalm. State Univ., 2003. 204 p. (In Russ.)

Bicheev B. A. Xinjiang Committee for Nationalities (China): a collection of Oirat manuscripts. In: [Memory of the World: Historical and Documentary Heritage of Buddhism]. Conf. proc. Moscow: Ippolitov Publ. Ltd., 2011. Pp. 240-244. (In Russ.)

Endon D. [Monuments of Tibetan and Mongolian Literatures: Fairy Tale Plots]. 2nd ed. Ulaanbaatar: Inst. of Lang. and Literat. (Mong. Acad. of Sc.), 2013. 201 p. (In Russ.)

Galdan Do. ['The Story of Usun Debiskertu Khan'. Poetic Teachings and Incense-Offering Texts]. Selected Clear Script texts. Urumqi: Xinjiang People's Publ. House, 2013. Pp. 3-19. (In Mong.)

Gerelmaa G. Brief Catalog of Oirat Manuscripts Kept by Institute of Language and Literature by Gerelmaa Guruuchin. Ulaanbaatar: Inst. of Lang. and Literat. (Mong. Acad. of Sc.), 2005. 270 p. (In Eng. and Mong.)

N. Ochirov's report about his journey to Astrakhan
Kalmyks in the summer of 1909. Izvestiya Russkogo komiteta dlya izucheniya Srednei $i$ Vostochnoi Azii. St. Petersburg, 1910. Pp. 6175. (In Russ.)

Orlova K. V. A description of Mongolian-language manuscripts and xylographs contained in Kalmykia's collections. Newsletter of Oriental Society. Is. 5. Moscow: Inst. of Oriental Studies of RAS, Kalm. Hum. Res. Inst. of RAS, 2002. 85 p. (In Russ.)

Sazykin A. G. [A Catalogue of Mongolian Manuscripts and Xylographs Contained in the Institute of Oriental Studies (USSR Acad. of Sc.)]. Vol. I. Moscow: Nauka, 1988. 507 p. (In Russ.)

The journey to Aleksandrovsky and Bagatsokhurovsky Uluses of Astrakhan Kalmyks. A report by N. Ochirov. Izvestiya Russkogo komiteta dlya izucheniya Srednei $i$ Vostochnoi Azii. St. Petersburg, 1913. Ser. II, No. 2. Pp. 78-91. (In Russ.)

Tserensodnom D. Didactic poems. In: [Essays on Mongolian Literature]. Vol. 2 (17 $\left.17^{\text {th }}-18^{\text {th }} \mathrm{cc}.\right)$. Ulaanbaatar: Inst. of Lang. and Literat. (Mong. Acad. of Sc.), 1976. Pp. 70-92. (In Mong.)

Tsevgee N. [The Adoption of Buddhism and Evolution of Oirat Culture and Society]. Ulaanbaatar, 2003. 220 p. (In Mong.)

Uspensky V. Catalogue of the Mongolian Manuscripts and Xylographs in the St. Petersburg State University Library. Tokyo: Institute for the Study of Languages and Cultures of Asia and Africa, 1999. 530 p. (In Eng.) 